\title{
Numerical solution of unsteady hydromagnetic natural convection flow of heat absorbing fluid past an impulsively moving vertical plate with ramped temperature
}

\author{
G. S. Seth* , S. Sarkar and G. K. Mahato \\ Department of Applied Mathematics, Indian School of Mines, Dhanbad-826004, India \\ *Corresponding author E-mail:gsseth_ism@yahoo.com
}

\begin{abstract}
A numerical investigation of unsteady hydromagnetic natural convection flow of a viscous, incompressible, electrically conducting and heat absorbing fluid past an impulsively moving vertical plate with ramped temperature embedded in a porous medium in the presence of thermal diffusion is carried out. The governing equations are solved numerically by Crank-Nicolson implicit finite difference scheme. The numerical solution for fluid velocity and fluid temperature are depicted graphically whereas the numerical values of skin friction and Nusselt number are presented in tabular form for various values of pertinent flow parameters. Natural convection flow near a ramped temperature plate is also compared with the flow near an isothermal plate.
\end{abstract}

Keywords: Natural convection, heat absorption, thermal diffusion, ramped temperature.

\section{Introduction}

Theoretical/Experimental investigation of hydrodynamic natural convection flow arising near solid bodies with different geometries embedded in a porous medium is of much significance due to its varied and wide applications in several areas of science and technology viz. chemical catalytic reactors, thermal insulators, heat exchanger devices, nuclear waste repositories, drying of porous solids, enhanced oil and gas recovery, underground energy transport etc. Several researchers investigated natural convection flow near a vertical plate embedded in a porous medium considering different aspects of the problem. Mention may be made of research studies of Cheng and Minkowycz [1], Nakayama and Koyama [2], Lai and Kulacki [3], Hsieh et al [4], Nield and Kuznetsov [5] and Gorla and Chamkha [6]. Comprehensive reviews of thermal convection in porous media along with its wide variety of engineering applications are well presented by Ingham and Pop [7], Vafai [8] and Nield and Bejan [9].

Investigation of the problems of hydromagnetic natural convection flow of an electrically conducting fluid within a fluid saturated porous medium is of much significance due to considerable influence of magnetic field on boundary layer control, geothermal energy extraction, enhanced recovery of petroleum products, thermal insulation of buildings, sensible heat storage bed, plasma studies and on the performance of many engineering devices viz. MHD energy generators, MHD pumps, MHD accelerators, MHD flow-meters, Plasma jet engines, controlled thermo-nuclear reactors etc. Keeping in view the importance of such study, Raptis and Kafousias [10] analyzed the effects of magnetic field on steady free convection flow through a porous medium bounded by an infinite vertical plate. Raptis [11] investigated time varying two-dimensional natural convection flow of a viscous, incompressible and electrically conducting fluid past an infinite vertical porous plate embedded in a porous medium. Takhar and Ram [12] considered hydromagnetic free convection flow of water at $4^{\circ} \mathrm{C}$ through porous medium. Chamkha [13] studied MHD free convection from a vertical plate embedded in a thermally stratified porous medium. Chamkha and Khanafer [14] discussed non-similar combined convection flow past a vertical surface embedded in a variable porosity medium. Jha [15] investigated MHD free convection and mass transfer flow past a uniformly accelerated moving vertical plate through porous medium when applied magnetic field is fixed with the moving plate. Aldoss et al [16] studied combined free and forced convection flow past a vertical plate embedded in a porous medium in the presence of a magnetic field. Kim [17] considered hydromagnetic natural convection flow past a vertical moving plate embedded in a porous medium. Makinde and Sibanda [18] considered steady hydromagnetic heat transfer by mixed convection flow past a vertical plate embedded in a uniform porous medium in the presence of uniform transverse magnetic field. Makinde [19] studied MHD mixed convection flow and mass transfer past a vertical porous plate with constant heat flux embedded in a porous medium. 
Fluid heat generation or absorption effects are of much significance in certain porous medium applications such as fluids undergoing exothermic and/ or endothermic chemical reaction (Vajravelu and Nayfeh [20]), applications in the field of nuclear energy (Crepeau and Clarksean [21]), convection in Earth's mantle (Mc Kenzie et al. [22]), post accident heat removal (Baker et al. [23]), fire and combustion modeling (Delichatsios [24]), development of metal waste from spent nuclear fuel (Westphal et al. [25]) etc. It is noticed that exact modeling of internal heat generation/ absorption is much complicated. It is found that some simple mathematical models yet idealized may express their average behavior for most of the physical situations. Taking into consideration this fact, investigation of such fluid flow problems is carried out by many researchers [26-30] in the past.

In all these investigations, analytical or numerical solution is obtained assuming conditions for the temperature at the plate to be continuous and well defined. However, several problems of practical interest may require non-uniform or arbitrary thermal conditions. Keeping in view this fact, several researchers investigated free convection flow from a vertical plate considering step discontinuities in the plate temperature. Mention may be made of the research studies of Hayday et al [31], Kelleher [32], Kao [33], Lee and Yovanovich [34], Chandran et al [35] and Seth and Ansari [36]. Seth and Ansari [36] investigated unsteady hydromagnetic natural convection flow of a viscous, incompressible, electrically conducting and heat absorbing fluid past an impulsively moving vertical plate with ramped temperature embedded in a fluid saturated porous medium taking into account the effect of thermal diffusion. Subsequently, Seth $e t$ al [37] considered the effects of Hall current on the problem studied by Seth and Ansari [36]. Patra et al [38] considered the effects of radiation on natural convection flow of a viscous and incompressible fluid near a stationary vertical flat plate with ramped temperature. Seth et al [39] studied effects of thermal radiation and rotation on unsteady hydromagnetic free convection flow past an impulsively moving vertical plate with ramped temperature in a porous medium. Recently, Nandkeolyar and Das [40] studied unsteady MHD free convection flow of a heat absorbing dusty fluid past a flat plate with ramped wall temperature.

As per authors' knowledge numerical solution for unsteady hydromagnetic natural convection flow past an impulsively moving vertical plate with ramped temperature in presence of thermal diffusion and heat absorption has not been obtained so far. Seth and Ansari [36] obtained analytical solution using Laplace transform technique. Therefore, aim of the present paper is to investigate the problem studied by Seth and Ansari [36] using numerical technique i.e. by Crank Nicolson implicit finite difference scheme.

\section{Formulation of the problem and its solution}

Consider unsteady flow of a viscous, incompressible, electrically conducting and heat-absorbing fluid past an infinite vertical plate embedded in a uniform porous medium. $x^{\prime}$-axis is taken along the plate in the upward direction and $y^{\prime}-$ axis normal to the plane of plate in the fluid. Fluid is permeated by a uniform transverse magnetic field $B_{0}$ applied parallel to $y^{\prime}$-axis. Initially, i.e. at time $t^{\prime} \leq 0$, both the fluid and plate are at rest and at a uniform temperature $T_{\infty}^{\prime}$. At time $t^{\prime}>0$, plate starts moving in $x^{\prime}$ direction with uniform velocity $U_{0}$. When $0<t^{\prime} \leq t_{0}$, temperature of the plate is raised or lowered to $T_{\infty}^{\prime}+\left(T_{w}^{\prime}-T_{\infty}^{\prime}\right) t^{\prime} / t_{0}$ and thereafter it is maintained at uniform temperature $T_{w}^{\prime}$ i.e. when $t^{\prime}>t_{0} \quad\left(t_{0}\right.$ being the characteristic time). Since plate is of infinite extent along $x^{\prime}$ and $z^{\prime}$ directions and electrically nonconducting, all physical quantities, except pressure, depend on $y^{\prime}$ and $t^{\prime}$ only. It is assumed that the induced magnetic field generated by fluid motion is neglected in comparison to the applied one. This assumption is valid for liquid metals and partially ionized fluids [41]. Also no external electric field is applied so the effect of polarization of fluid is negligible. This corresponds to the case where no energy is added or extracted from the fluid by electrical means [41].

Keeping in view the assumptions made above, the governing equations for natural convection flow of a viscous, incompressible, electrically conducting and heat absorbing fluid in a uniform porous medium, under Boussinesq approximation, in the presence of thermal diffusion are given by

$$
\begin{aligned}
& \frac{\partial u^{\prime}}{\partial t^{\prime}}=v \frac{\partial^{2} u^{\prime}}{\partial y^{\prime 2}}-\frac{\sigma B_{0}^{2}}{\rho} u^{\prime}-\frac{v}{K^{\prime}} u^{\prime}+g \beta^{\prime}\left(T^{\prime}-T_{\infty}^{\prime}\right), \\
& \frac{\partial T^{\prime}}{\partial t^{\prime}}=\frac{k_{1}}{\rho c_{p}} \frac{\partial^{2} T^{\prime}}{\partial y^{\prime 2}}-\frac{Q_{0}}{\rho c_{p}}\left(T^{\prime}-T_{\infty}^{\prime}\right),
\end{aligned}
$$

where $u^{\prime}, K^{\prime}, Q_{0}, \rho, v, \sigma, k_{1}$ and $c_{p}$ are, respectively, fluid velocity, permeability of porous medium, heat absorption coefficient, density, kinetic coefficient of viscosity, electrical conductivity, thermal conductivity and specific heat at constant pressure.

The initial and boundary conditions are 
$u^{\prime}=0, T^{\prime}=T_{\infty}^{\prime} \quad$ for $y^{\prime} \geq 0$ and $t^{\prime} \leq 0$,

$u^{\prime}=U_{0}$ at $y^{\prime}=0$ for $t^{\prime}>0$,

$T^{\prime}=T_{\infty}^{\prime}+\left(T_{w}^{\prime}-T_{\infty}^{\prime}\right) t^{\prime} / t_{0}$ at $y^{\prime}=0$ for $0<t^{\prime} \leq t_{0}$,

$T^{\prime}=T_{w}^{\prime}$ at $y^{\prime}=0$ for $t^{\prime}>t_{0}$,

$u^{\prime} \rightarrow 0, T^{\prime} \rightarrow T_{\infty}^{\prime}$ as $y^{\prime} \rightarrow \infty$ for $t^{\prime}>0$.

Introducing the non dimensional variables and parameters

$y=y^{\prime} / U_{0} t_{0}, u=u^{\prime} / U_{0}, t=t^{\prime} / t_{0}, T=\left(T^{\prime}-T_{\infty}^{\prime}\right) /\left(T_{w}^{\prime}-T_{\infty}^{\prime}\right), \quad M=\sigma B_{0}{ }^{2} v / \rho U_{0}^{2}, K_{1}=K^{\prime} U_{0}^{2} / v^{2}$,

$G_{r}=g \beta^{\prime} v\left(T_{w}^{\prime}-T_{\infty}^{\prime}\right) / U_{0}^{3}, P_{r}=v \rho c_{p} / k_{1}$ and $\phi=v Q_{0} / \rho c_{p} U_{0}^{2}$,

equations (1) and (2), in non dimensional form, become

$\frac{\partial u}{\partial t}=\frac{\partial^{2} u}{\partial y^{2}}-M^{2} u-\frac{u}{K_{1}}+G_{r} T$

$\frac{\partial T}{\partial t}=\frac{1}{P_{r}} \frac{\partial^{2} T}{\partial y^{2}}-\phi T$

where $M^{2}, K_{1}, G_{r}, P_{r}, \phi$ and $T$ are, respectively, magnetic parameter, permeability parameter, Grashof number, Prandtl number and dimensionless heat absorption coefficient and non-dimensional fluid temperature.

According to the above non-dimensionalisation process, characteristic time $t_{0}$ can be defined as

$t_{0}=v / U_{0}^{2}$.

Using (4) and (7) the initial and boundary conditions (3a) to (3e), in non-dimensional form, become

$u=0, \quad T=0 \quad$ for $y \geq 0$ and $t \leq 0$,

$u=1$ at $y=0$ for $t>0$,

$T=t$ at $y=0$ for $0<t \leq 1$,

$T=1$ at $y=0$ for $t>1$,

$u \rightarrow 0, \quad T \rightarrow 0$ as $y \rightarrow \infty$ for $t>0$

It is evident from equations (5) and (6) that energy equation (6) is uncoupled from the momentum equation (5). Therefore, we obtain first the solution for fluid temperature $T(y, t)$ by solving equation (6) and then using it in equation (5) solution for the fluid velocity $u(y, t)$ is obtained.

\section{Numerical solution}

Equations (5) and (6) subject to the conditions (8a) to (8e) are solved by employing Crank-Nicolson implicit finite difference scheme. The method is unconditionally stable and it is second order accurate in space and time [42]. Region of integration considered is a rectangle with $y_{\max }=6$ (corresponding to $y \rightarrow \infty$ ) and $t_{\max }=2$ where $\Delta y=0.05$ and $\Delta t=0.01$ such that the computational domain is divided into $121 \times 201$ grid points. Assumption of $y_{\max }=6$ is justified since boundary conditions (8e) is satisfied within tolerance limit of $10^{-5}$. Mesh size $\Delta y=0.05$ with time step $\Delta t=0.01$ is finalized after comparing results in this case with the results obtained when mesh size is reduced to $50 \%$ of the present case and it is noticed that the difference between these two results is less than half a unity in the fourth decimal place. Numerical solutions are obtained for both ramped temperature and isothermal plates for required number of iterations. It has been found that the absolute difference between the numerical values of $\mathrm{u}$ and $T$ obtained for two consecutive time steps is less than $10^{-4}$. Hence the scheme designed is stable. Moreover, CrankNicolson scheme has local truncation error of $O\left\{(\Delta y)^{2}+(\Delta t)^{2}\right\}$ which tends to zero as $\Delta y$ and $\Delta t$ tend to zero which justifies consistency. Stability and consistency together ensure convergence of the scheme. 


\section{Results and discussion}

In order to analyze the effects of magnetic field, thermal buoyancy force, heat absorption, thermal diffusion and time on the flow-field, numerical solution of fluid velocity $u$ for both ramped temperature and isothermal plates, is depicted graphically versus boundary layer coordinate $y$ in Figures 1 to 5 for various values of magnetic parameter $M^{2}$, Grashof number $G_{r}$, heat absorption coefficient $\phi$, Prandtl number $P_{r}$ and time $t$ keeping permeability parameter fixed at $K_{1}=0.4$. Figure 1 displays a comparison between exact solution obtained by Seth and Ansari [36] and the present numerical solution. It is evident from Figure 1 that there is an excellent agreement between the two solutions. Figure 1 also demonstrates the effects of magnetic field on the fluid velocity $u$ for both ramped temperature and isothermal plates. It is noticed from Figure 1 that, for both ramped temperature and isothermal plates, $u$ decreases on increasing $M^{2}$. This implies that magnetic field has a tendency to retard fluid velocity for both ramped temperature and isothermal plates. This is due to the fact that application of a magnetic field to an electrically conducting fluid gives rise to a resistive force, known as Lorentz force, which has a tendency to retard the fluid motion. Figure 2 illustrates the influence of thermal buoyancy force on fluid velocity $u$ for both ramped temperature and isothermal plates. It is perceived from Figure 2 that, for both ramped temperature and isothermal plates, $u$ increases on increasing $G_{r}$. This implies that thermal buoyancy force tends to accelerate fluid velocity for both ramped temperature and isothermal plates. Figure 3 depicts the influence of heat absorption coefficient on fluid velocity $u$ for both ramped temperature and isothermal plates. It is evident from Figure 3 that, for both ramped temperature and isothermal plates, $u$ decreases on increasing $\phi$. This implies that heat absorption tends to retard fluid velocity for both ramped temperature and isothermal plates. Figure 4 demonstrates the effects of Prandtl number on fluid velocity $u$ for both ramped temperature and isothermal plates. It is noticed from Figure 4 that, for both ramped temperature and isothermal plates, $u$ increases on decreasing $P_{r}$. Prandtl number $P_{r}$ represents the relative strength of viscosity to thermal diffusivity of the fluid, Prandtl number $P_{r}$ decreases on increasing thermal diffusivity of the fluid. This implies that thermal diffusion tends to accelerate fluid velocity for both ramped temperature and isothermal plates. Figure 5 presents the influence of time on fluid velocity $u$ for both ramped temperature and isothermal plates. As time $t$ increases fluid velocity $u$ increases for both ramped temperature and isothermal plates. This implies that, fluid velocity is getting accelerated with the progress of time for both ramped temperature and isothermal plates.

The numerical solution of fluid temperature $T$ is displayed graphically in Figures 6 to 8 for different values of $P_{r}$, $\phi$ and $t$. It is found from Figures 6 to 8 that, for both ramped temperature and isothermal plates, fluid temperature $T$ decreases on increasing $P_{r}$ and $\phi$ while it increases on increasing $t$. This implies that thermal diffusion tends to enhance fluid temperature whereas heat absorption has a reverse effect on it for both ramped temperature and isothermal plates. There is an enhancement in fluid temperature with the progress of time for both ramped temperature and isothermal plates. From Figures 1 to 8 it is also evident that both fluid velocity $u$ and fluid temperature $T$ attain a distinctive maximum value near the surface of plate and then decrease properly on increasing boundary layer coordinate $y$ to approach free stream value. It is also perceived from Figures 1 to 8 that fluid velocity is slower and fluid temperature is lower in case of ramped temperature plate than that of isothermal plate.

Numerical values of skin friction $\tau$, for both ramped temperature and isothermal plates, are presented in tabular form in Tables 1 and 2 for various values $M^{2}, G_{r}, \phi$ and $t$ taking $K_{1}=0.4$ and $P_{r}=0.71$ while those of Nusselt number $N u$ are given in Tables 3 and 4 for different values of $\phi, t$ and $P_{r}$. It is found from Tables 1 and 2 that, for both ramped temperature and isothermal plates, skin friction $\tau$ increases on increasing $M^{2}$ and $\phi$ whereas it decreases on increasing $G_{r}$ and $t$. This implies that, for both ramped temperature and isothermal plates, magnetic field and heat absorption tend to enhance skin friction whereas thermal buoyancy force has a reverse effect on it and skin friction is getting reduced with the progress of time. It is noticed from Tables 3 and 4 that, for both ramped temperature and isothermal plates, Nusselt number $\mathrm{Nu}$ increases on increasing $\phi$ and $P_{r}$ whereas it increases for ramped temperature plate and decreases for isothermal plate on increasing $t$. This implies that, for both ramped temperature and isothermal plates, thermal diffusion tends to reduce rate of heat transfer at the plate whereas heat absorption has a reverse effect on it. Rate of heat transfer at ramped temperature plate is getting enhanced whereas, at isothermal plate, it is getting reduced with the progress of time. 


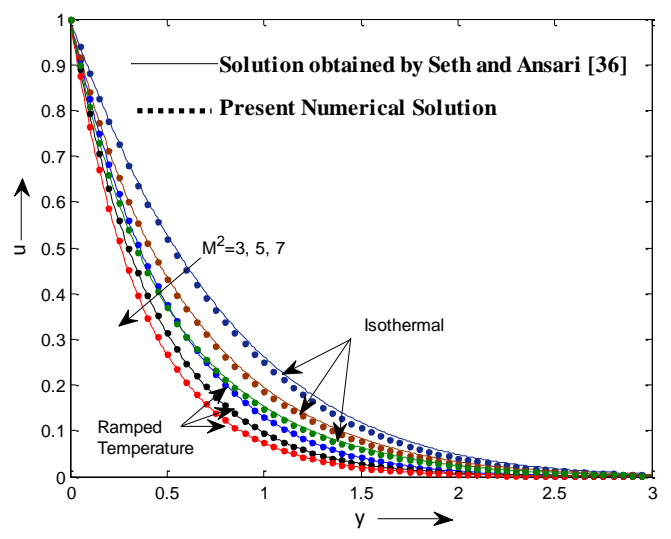

Fig. 1: Velocity profiles when $G_{r}=4$, $\phi=2, P_{r}=0.71$ and $t=0.5$

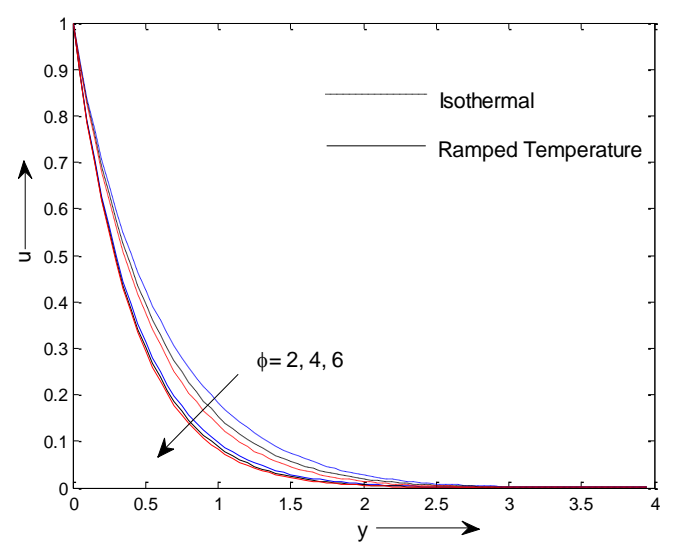

Fig. 3: Velocity profiles when $M^{2}=5$, $G_{r}=4, P_{r}=0.71$ and $t=0.5$

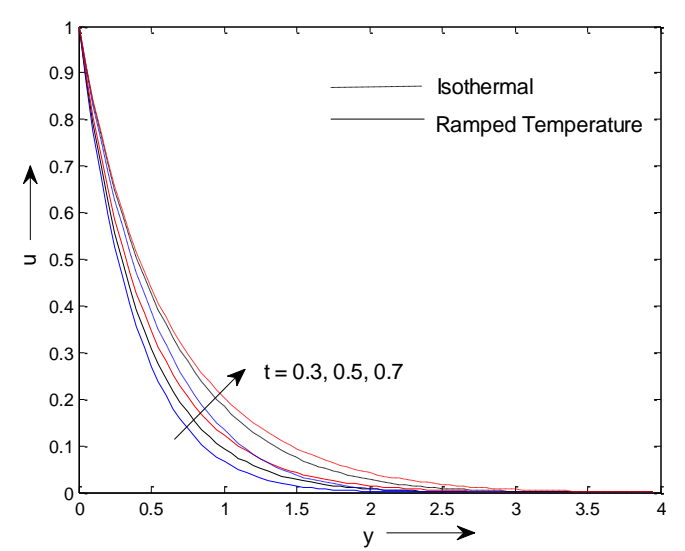

Fig. 5: Velocity profiles when $M^{2}=5$, $G_{r}=4, \phi=2$ and $P_{r}=0.71$

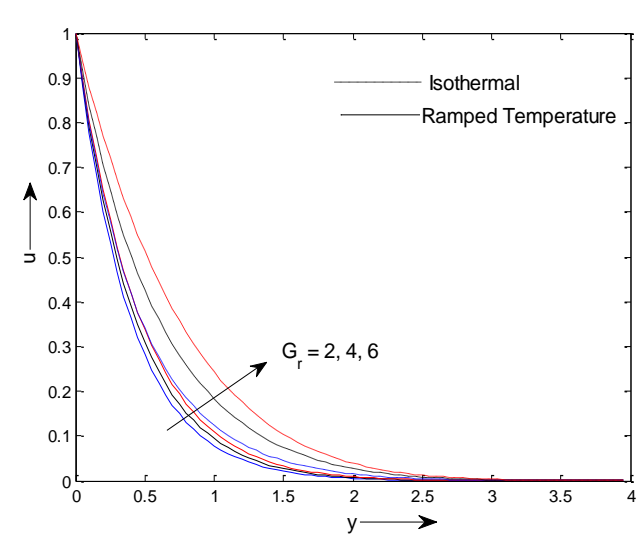

Fig. 2: Velocity profiles when $M^{2}=5$, $\phi=2, P_{r}=0.71$ and $t=0.5$

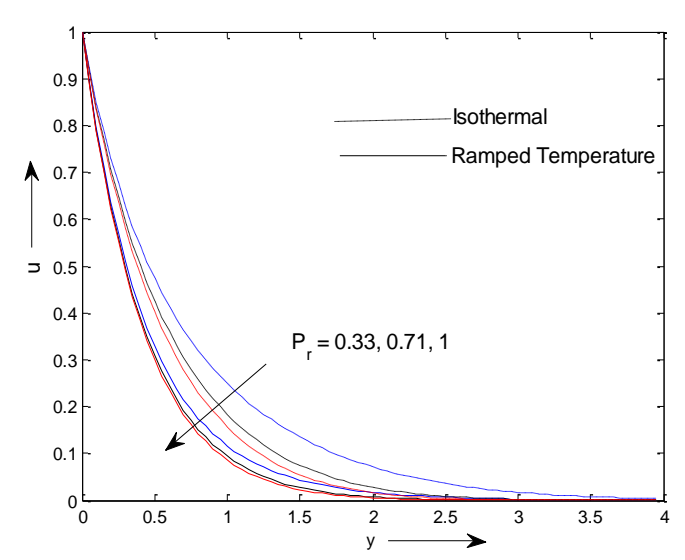

Fig. 4: Velocity profiles when $M^{2}=5$ $G_{r}=4, \phi=2$ and $t=0.5$

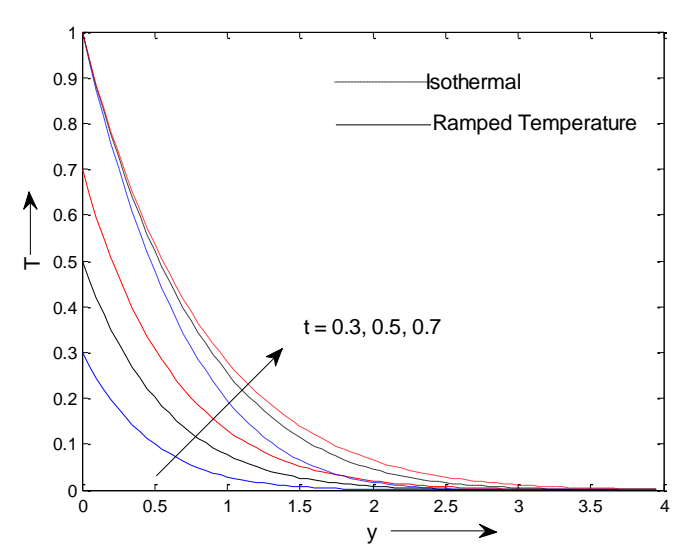

Fig. 6: Temperature profiles when $P_{r}=0.71$ and $\phi=2$ 


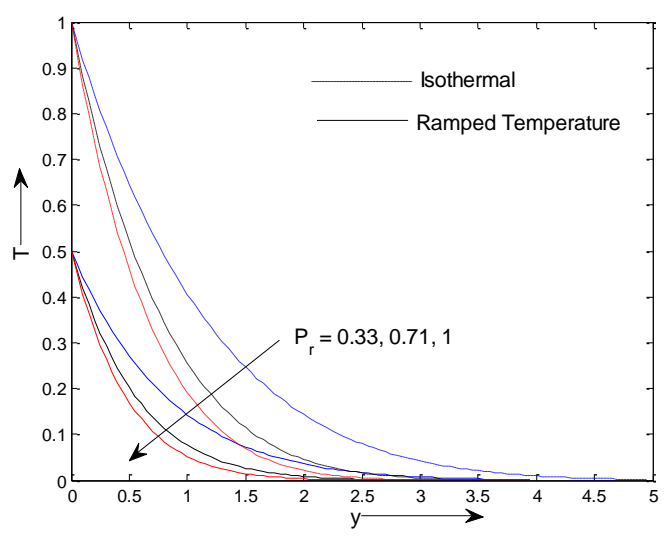

Fig. 7: Temperature profiles when $t=0.5$ and $\phi=2$

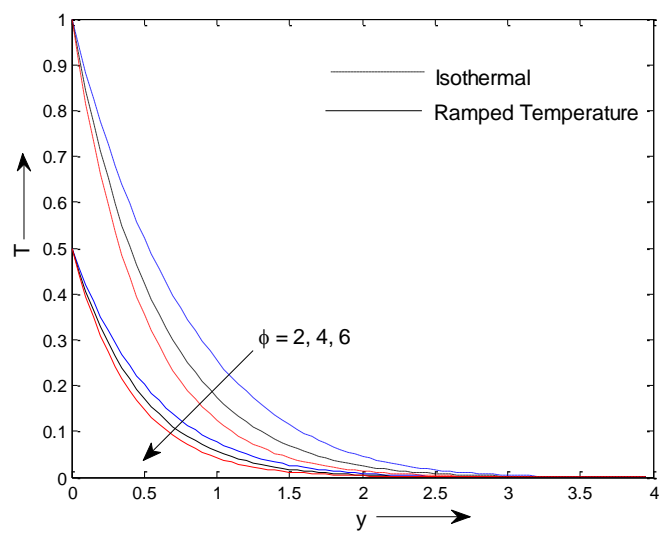

Fig. 8: Temperature profiles when $t=0.5$ and $P_{r}=0.71$

Table 1: Skin friction $-\tau$ when $t=0.5$ and $\phi=2$.

\begin{tabular}{c|ccc|cccc}
\hline \multirow{2}{*}{$M_{\downarrow}^{2} \quad \mathrm{G}_{\mathrm{r} \rightarrow}$} & \multicolumn{3}{|c|}{ Ramped Temperature Plate } & \multicolumn{3}{c}{ Isothermal Plate } \\
\cline { 2 - 8 } & 2 & 4 & 6 & 2 & 4 & 6 \\
\hline 3 & 2.1409 & 1.9315 & 1.7221 & 1.8232 & 1.2962 & 0.7691 \\
\hline 5 & 2.5411 & 2.3442 & 2.1472 & 2.2547 & 1.7713 & 1.2880 \\
\hline 7 & 2.8928 & 2.7062 & 2.5195 & 2.6302 & 2.1811 & 1.7319 \\
\hline
\end{tabular}

Table 2: Skin friction $-\tau$ when $M^{2}=5$ and $G_{r}=4$

\begin{tabular}{c|ccc|c|c|c}
\hline \multirow{2}{*}{$\phi_{\downarrow} \quad \mathrm{t} \rightarrow$} & \multicolumn{3}{|c|}{ Ramped Temperature Plate } & \multicolumn{3}{c}{ Isothermal Plate } \\
\cline { 2 - 9 } & 0.3 & 0.5 & 0.7 & 0.3 & 0.5 & 0.7 \\
\hline 2 & 2.5478 & 2.3442 & 2.1458 & 1.8603 & 1.7713 & 1.7428 \\
\hline 4 & 2.5561 & 2.3668 & 2.1866 & 1.9155 & 1.8532 & 1.8393 \\
\hline 6 & 2.5633 & 2.3853 & 2.2182 & 1.9615 & 1.9149 & 1.9071 \\
\hline
\end{tabular}

Table 3: Nusselt number $-\mathrm{Nu}$ when $P_{r}=0.71$

\begin{tabular}{c|ccc|ccc}
\hline \multirow{2}{*}{$\phi_{\downarrow} \quad \mathrm{t} \rightarrow$} & 0.3 & 0.5 & 0.7 & \multicolumn{3}{c}{ Isothermal Plate } \\
\cline { 2 - 7 } & \multicolumn{3}{|c|}{ Ramped Temperature Plate } & 0.3 & 0.5 & 0.7 \\
\hline 2 & 0.6170 & 0.8741 & 1.1205 & 1.3562 & 1.2540 & 1.2201 \\
\hline 4 & 0.7038 & 1.0464 & 1.3848 & 1.7501 & 1.6996 & 1.6890 \\
\hline 6 & 0.7832 & 1.1977 & 1.6106 & 2.0933 & 2.0670 & 2.0638 \\
\hline
\end{tabular}

Table 4: Nusselt number $-\mathrm{Nu}$ when $\phi=2$

\begin{tabular}{c|ccc|ccc}
\hline \multirow{2}{*}{$P_{r \downarrow} \quad \mathrm{t}_{\rightarrow}$} & \multicolumn{3}{|c|}{ Ramped Temperature Plate } & \multicolumn{3}{c}{ Isothermal Plate } \\
\cline { 2 - 7 } & 0.3 & 0.5 & 0.7 & 0.3 & 0.5 & 0.7 \\
\hline 0.33 & 0.4807 & 0.7136 & 0.9443 & 1.2458 & 1.1659 & 1.1527 \\
\hline 0.71 & 0.7038 & 1.0464 & 1.3848 & 1.7501 & 1.6996 & 1.6890 \\
\hline 1 & 0.8350 & 1.2416 & 1.6432 & 2.0722 & 2.0167 & 2.0042 \\
\hline
\end{tabular}




\section{Conclusions}

For both ramped temperature and isothermal plates,

- Magnetic field and heat absorption tend to retard fluid velocity whereas thermal buoyancy force and thermal diffusion have reverse effect on it.

- Fluid velocity is getting accelerated with the progress of time.

- Thermal diffusion tends to enhance fluid temperature whereas heat absorption has a reverse effect on it.

- There is an enhancement in fluid temperature with the progress of time.

- Magnetic field and heat absorption tend to enhance skin friction whereas thermal buoyancy force has a reverse effect on it.

- Skin friction is getting reduced with the progress of time.

- Thermal diffusion tends to reduce rate of heat transfer at the plate whereas heat absorption has a reverse effect on it. Rate of heat transfer at ramped temperature plate is getting enhanced whereas, at isothermal plate, it is getting reduced with the progress of time.

\section{References}

[1] P. Cheng and W.J. Minkowycz, Free convection about a vertical flat plate embedded in a porous medium with application to heat transfer from a dike, J. Geophys. Res., 82 (1977) 2040-2044.

[2] A. Nakayama and H. Koyama, A general similarity transformation for combined free and forced convection flows within a fluid saturated porous medium, ASME J. Heat Transfer, 109 (1987) 1041-1045.

[3] F.C. Lai and F.A. Kulacki, Non-Darcy Mixed Convection Along a Vertical Wall in a Saturated Porous Medium, Trans. ASME J. Heat Transf., 113 (1991) 252-255.

[4] J.C. Hsieh, T.S. Chen and B.F. Armaly, Non-similarity solutions for mixed convection from vertical surfaces in porous media: variable surface temperature or heat flux, Int. J. Heat Mass Transfer, 36 (1993) 1485-1493.

[5] D.A. Nield and A.V. Kuznetsov, The Cheng-Minkowych problem for natural convective boundary layer flow in a porous medium saturated by a nanofluid, Int. J. Heat Mass Transfer 52 (2009) 5792-5795.

[6] R.S.R. Gorla, and A.J. Chamkha, Natural convective boundary layer flow over a non-isothermal vertical plate embedded in a porous medium saturated with nanofluid. Nanoscale and Microscale, Thermophys. Engng., 15 (2011) 81-94.

[7] D.B. Ingham and I. Pop, Transport Phenomena in Porous Media, vol. III, Elsevier, Oxford, 2005.

[8] K. Vafai, Handbook of Porous Media, second ed., Taylor \& Francis, New York, 2005.

[9] D.A. Nield and A. Bejan, Convection in Porous Media, third ed., Springer, New York, 2006.

[10] A. Raptis and N. Kafousias, Heat transfer in flow through a porous medium bounded by an infinite vertical plate under the action of magnetic field, Int. J. Energy Res., 6 (1982) 241-245.

[11] A. Raptis, Flow through a porous medium in the presence of a magnetic field, Int. J. Energy Res., 10 (1986) 97-100.

[12] H.S. Takhar and P.C. Ram, Magnetohydrodynamic free convection flow of water at $4^{\circ} \mathrm{C}$ through a porous medium, Int. Comm. Heat Mass Transfer, 21(1994) 371-376.

[13] A.J. Chamkha, MHD Free Convection from a Vertical Plate Embedded in a Thermally Stratified Porous Medium, Fluid/Particle Separation Journal, 9 (1996) 195-206.

[14] A.J. Chamkha and K. Khanafer, Non-Similar Combined Convection Flow Over a Vertical Surface Embedded in a Variable Porosity Medium, J. Porous Media, 2 (1999) 231-249.

[15] B.K. Jha, MHD free convection and mass-transform flow through a porous medium, Astrophys. Space Sci., 175 (1991) $283-289$.

[16] T.K. Aldoss, M.A. Al-Nimr, M.A. Jarrah and B.J. Al-Shaer, Magnetohydrodynamic mixed convection from a vertical plate embedded in a porous medium, Numer. Heat Transfer, 28 (1995) 635-645.

[17] Y.J. Kim, Unsteady MHD convective heat transfer past a semi-infinite vertical porous moving plate with variable suction, Int. J. Engng. Sci., 38 (2000) 833-845.

[18] O.D. Makinde and P. Sibanda, Magnetohydrodynamic Mixed Convective Flow and Heat and Mass Transfer Past a Vertical Plate in a Porous Medium with Constant Wall Suction, J. Heat Transf., 130 (2008) Article No. 112602, 8 pages.

[19] O.D. Makinde, On MHD boundary-layer flow and mass transfer past a vertical plate in a porous medium with constant heat flux, Int. J. Numer. Methods Heat Fluid Flow, 19 (2009) 546-554.

[20] K. Vajravelu and J. Nayfeh, Hydromagnetic convection at a cone and a wedge, Int. Comm. Heat Mass Transfer, 19 (1992) $701-710$.

[21] J.C. Crepeau and R. Clarksean, Similarity solutions of natural convection with internal heat generation, ASME J. Heat Transfer, 119 (1997) 183-185.

[22] D.P. Mckenzie, J.M. Roberts and N.O. Weiss, Convection in the Earth's mantle: towards a numerical simulation, J. Fluid. Mech., 62 (1974) 465-538.

[23] L. Baker, R.E. Faw and F.A. Kulacki, Post-accident heat removal part-I: heat transfer within an internally heated nonboiling liquid layer, J. Nucl. Sci. Eng., 61 (1976) 222-230.

[24] M.A. Delichatsios, Air entrainment into buoyant jet flames and pool fires in DiNenno, P.J, et al (Eds.) The SFPA handbook of fire protection engineering, NFPA publications, Quincy, M.A., (1988) 306-314.

[25] B.R. Westphal, D.D. Keiser, R.H. Rigg and D.V. Loug, Production of metal waste forms from spent nuclear fuel treatment, DOE Spent Nuclear Fuel Conference, Salt Lake City, UT, (1994) 288-294.

[26] D. Moalem, Steady state heat transfer with porous medium with temperature dependent heat generation, Int. J. Heat Mass Transfer, 19 (1976) 529-537.

[27] A.J. Chamkha, Unsteady MHD convective heat and mass transfer past a semi-infinite vertical permeable moving plate with heat absorption, Int. J. Engng Sci., 42 (2004) 217-230. 
[28] F.S. Ibrahim, I.A. Hassanien and A.A. Bakr, Unsteady magnetohydrodynamic micro-polar fluid flow and heat transfer over a vertical porous plate through a porous medium in the presence of thermal and mass diffusion with a constant heat source, Canadian J. Phys., 82 (2004) 775790 .

[29] M. M. Rahman and M.A. Sattar, Magnetohydrodynamic convective flow of a micropolar fluid past a continuously moving vertical porous plate in the presence of heat generation/absorption, ASME J. Heat Trans., 128 (2006) 142-152.

[30] B.K. Jha and A.O. Ajibade, Free convective flow of heat generating/absorbing fluid between vertical porous plates with periodic heat input, Int. Comm. Heat Mass Transfer, 36 (2009) 624-631.

[31] A.A. Hayday, D.A. Bowlus and R.A. McGraw, Free convection from a vertical plate with step discontinuities in surface temperature, ASME J. Heat Transfer, 89 (1967) 244-250.

[32] M. Kelleher, Free convection from a vertical plate with discontinuous wall temperature, ASME J. Heat Transfer, 93 (1971) $349-356$.

[33] T.T. Kao, Laminar free convective heat transfer response along a vertical flat plate with step jump in surface temperature, Lett. Heat Mass Transfer, 2 (1975) 419-428.

[34] S. Lee and M.M. Yovanovich, Laminar natural convection from a vertical plate with a step change in wall temperature, ASME J. Heat Transfer, 113 (1991) 501-504.

[35] P. Chandran, N.C. Sacheti and A.K. Singh, Natural convection near a vertical plate with ramped wall temperature, Heat Mass Transfer, 41 (2005) 459-464

[36] G.S. Seth and Md. S. Ansari, MHD natural convection flow past an impulsively moving vertical plate with ramped wall temperature in the presence of thermal diffusion with heat absorption, Int. J. Appl. Mech. Eng., 15 (2010) 199-215.

[37] G.S. Seth, G.K. Mahato, S. Sarkar and Md.S. Ansari, Effects of Hall Current on Hydromagnetic Natural Convection Flow of a Heat Absorbing Fluid past an Impulsively Moving Vertical Plate with Ramped Temperature, Int. J. Appl. Math. Res., 1(2012) $462-486$.

[38] R.R. Patra, S. Das, R.N. Jana and S.K. Ghosh, Transient Approach to Radiative Heat Transfer Free Convection Flow with Ramped Wall Temperature, J. Appl. Fluid Mech., 5 (2012) 9-13.

[39] G.S. Seth, R. Nandkeolyar and Md. S. Ansari. Effects of Thermal Radiation and Rotation on Unsteady Hydromagnetic Free Convection Flow Past an Impulsively Moving Vertical Plate with Ramped Temperature in a Porous Medium, J. Appl. Fluid Mech., 6 (2013) 27-38.

[40] R. Nandkeolyar and M. Das, Unsteady MHD free convection flow of a heat absorbing dusty fluid past a flat plate with ramped wall temperature, Afr. Mat. (2013) DOI 10.1007/s13370-013-0151-9.

[41] K.R. Cramer and S. Pai, Magnetohydrodynamics for Engineers and Applied Physicists. McGraw Hill Book Company, New York, 1973.

[42] H.M. Antia, Numerical Methods for Scientists and Engineers, Tata McGraw-Hill Publishing Company Limited, New Delhi, 1991. 